\section{Pig Machine}

\section{Practice at Hanna}

by A. J. Macdonald

$\mathrm{H}^{\mathrm{A}}$ ANNA FURNACE CORP., Buffalo, is a producer of merchant iron and thus the pig machine constitutes the finishing end of the plant. Every effort is made to produce a pig iron that customers will like.

There are three pig machines, Nos. 1 and 2 being identical, and each of the three is doublestrand, gear-driven, and $140 \mathrm{ft} 9$ in. center-tocenter of sprockets, horizontally. The molds are supported on 18 in. pitch chain links with wheels running on $70-1 \mathrm{~b}$ rails. There are two molds on each link and 392 molds per strand. The average size of pig is $32 \mathrm{lb}$. The molds are made in the plant foundry, usually from about 2 pct silicon malleable iron. The pig-machine wheels are of tool steel which has been found to far outlast anything else. The first tool-steel wheels were installed $8 \mathrm{yr}$ ago, and are still good for many

A. J. Macdonald is with Hanna Furnace Corp., Buffalo. This is a paper to be presented before the Annual Blast Furnace, Coke Oven and Raw Materials Conference, April 10-12, at Cincinnati.

more years. Each strand is driven by a $15 \mathrm{hp}$ variable-speed motor. The speed of each strand can be regulated between 22 and $45 \mathrm{fpm}$. No. 3 machine was built and placed in operation in 1942. It is a double-strand, gear-driven, $155 \mathrm{ft}$ 2 in. center-to-center of sprockets horizontally. On this machine there are 432 molds per strand, each strand driven by a $25 \mathrm{hp}$ variable-speed motor. The speed of each strand may be regulated from 20 to $40 \mathrm{fpm}$.

Each pig machine has a conventional pouring box, runner and " $T$ " runner to the strands. In the main runner two brick skimmers are placed before the dam. On each machine a ladle skimmer has been installed at the end of a structural steel beam of rugged design. This skimmer is counter-weighted and raised and lowered by a hand-operated winch, and a ladle can be tilted to the point where all the iron will run out and the kish still be held back. In the pig-machine building there are three overhead cranes, an Alliance single-hook crane of 75-tons capacity, with auxiliary 10-ton hoist, a Cleveland 80-ton crane with bale and ladle trunion hooks, also a 25-ton hook on a separate trolley, and a Morgan 30 -ton single-hook crane with auxiliary 5 -ton

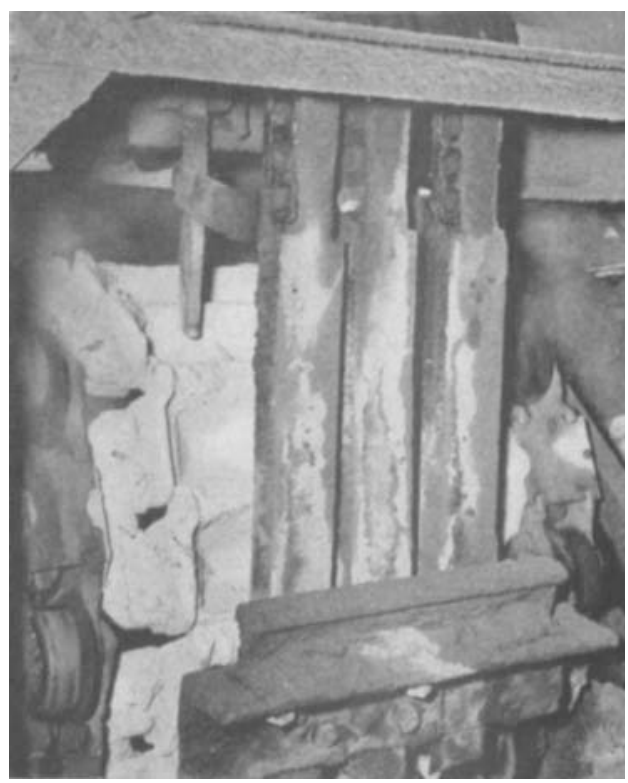

Pig Knocker on the head end of the pig machine.

hoist and magnet control for handling scrap, clay boxes, etc. A stationary tilting hoist is installed at No. 3 pig machine for pouring iron on this strand.

The ladles are the open-top, short-pour type, and are of 60 and 75 gross ton capacity. At the head end of each machine there is a pig knocker of very satisfactory and simple design. A shaft is installed over the end of the chain and rails hung from it at a position where they can swing against the mold at the time the pig should drop out. To make the rails swing against the mold, an arm extends toward the molds coming up over the head end of the machine and the side of the mold pushes the arm out, which in turn pushes the rails out and then releases them to fall against the mold as it starts to go under the sprocket. This simple arrangement is very satisfactory and requires no maintenance for long periods of time, and also practically eliminates stickers on an otherwise well kept pig machine.

For cooling the iron sprays are used, made from 27 in. sections of 6 -in. pipe welded shut on the ends. A slot is cut lengthwise of the pipe and the water spills downward on the pig at very low pressure. The 6-in. pipe is fed by an $11 / 4$-in. waterline. These sprays are installed as far up towards the head end of the big machine as is possible to put them.

In pouring iron of over 8 pct silicon it is necessary to air-cool the iron, so water sprays were installed on the underside of the molds on the ascending side at the upper end of the machine. These are just perforated pipe with water under pressure and do a very satisfactory job of cooling the molds when no water can be put on the iron. The thermal shock to pig molds as they go around the cycle on the pig machine is not inconsiderable, it being in the range of a $1000^{\circ} \mathrm{F}$ difference from low to high in 5-min time. This of course does not help mold life, and in the search for longer mold life many different irons have been tried, with additions of molybdenum, vanadium, etc., to the foundry ladle. But, as al- 
ready indicated, malleable iron, with the addition of a little steel scrap in the foundry ladle, has always been the final choice. A mold of uniform wall thickness has been found to be superior. Carbon molds have been tried, with eight molds installed together in one strand. They were used for two weeks and at the end of that time they showed no sign of wear or burning. The carbon molds have a future, but adapting them to a machine already built for iron molds would be very difficult.

Of extreme importance is control of the mold coating. A dead-burned dolomite and powdered coal are used in proportions of 75 pct dolomite and 25 pet coal by volume. The burned dolomite is shipped in container cars and is unloaded into a tank with a capacity of two car loads. Aerators have been installed to prevent the dolomite from sticking in the bin and the results are very satisfactory. At the bottom of the tank there is a screw conveyor leading to a hopper at the bottom of a bucket elevator, and also at the bottom of the elevator is another hopper where powdered coal is measured in. The bucket elevator discharges into a hopper over the slaking tank and between the hopper and slaking tank is a volume-measuring device to deliver the correct amount of material for each batch of mold coat. The coal is crushed and powdered in a ball mill in a separate room adjacent to the limehouse and brought to the elevator in a hand truck. The mold coat is prepared by first heating water in a slaking tank with a steam jet. The coating mixture is then put in the slaking tank, which has a capacity of 550 gal, and agitated with a motor-driven agitator for about $15 \mathrm{~min}$, enough water added to bring the specific gravity to 1.12 , and then the solution is pumped to the storage tank which has a capacity of 3000 gal and holds enough to last for $16 \mathrm{hr}$. In the storage tank is a motor-driven agitator keeping the mold coat stirred up, and from the storage tank the coating is continuously pumped to the three pig machines. The pumps are Aurora centrifugals driven by a $1 \mathrm{hp}$ motor at a speed of $1750 \mathrm{rpm}$. They have a capacity of 20 to 50 gal per min at $40-\mathrm{ft}$ head. To fill the tanks at the pig machines the operator only has to open a valve and close it when the tank is full. There is a return line from the machines to the storage tank so there can be no settling or precipitation of the lime in the pipes. One man on day turn only takes care of preparing the mold coat for three machines for
$24 \mathrm{hr}$. The mold coat is aspirated into the molds with a steam jet from the tanks beneath the machines.

One other feature of the pig machine is the depressed track and pouring stand for treating high-sulphur iron. As the sulphur limit is 0.050 max, iron that is 0.047 or 0.048 sulphur is of ten treated so the cold iron will not be over 0.050 . An empty ladle is put under the pouring stand on the depressed track and a full ladle poured into it over the stand.

At the head end of the pig machines there are three tracks for pig-iron cars, and a cable-car haul system between tracks. The car man operates the car-haul, with pushbutton control, from a bridge walkway that spans the tracks.

When a cast is finished at the furnace, the blower fills out a card showing ladle numbers and the time cast was finished, and any remarks such as instructions to hold the iron until sulphur is known. The conductor on the ladle engine gives this card to the pig-machine foreman when he delivers the iron. Delivery of hot metal to the pig machine comes first in the transportation department. All the information that has to be exchanged between furnaces, pig machine, and scales, is reduced to writing, as with four furnaces operating on different irons the chance of a mix-up in irons is very possible, and to put a ladle of iron that is outside the analysis on a pile of iron that perhaps has a thousand tons in it is a major calamity.

Because each furnace is usually on a different grade of iron it is necessary to have a separate set of ladles for each furnace. Ladle-lining life is well over 10,000 gross tons, and it is rare to lose more than the inner lining. Ladles are dumped and skulled every $12 \mathrm{hr}$ when they are on the run.

Pouring temperatures on standard iron range from $2400^{\circ}$ to $2600^{\circ} \mathrm{F}$, mostly between $2500^{\circ}$ and $2600^{\circ} \mathrm{F}$. There are occasions when better looking iron will result if the temperature is allowed to go down a little, but as a general rule the hotter the iron is when it is poured, the better looking the pigs. Therefore the objective is always to pour hot. On the iron-carbon equilibrium diagram, the temperature at which primary austenite begins to solidify goes up rapidly as the silicon in the iron goes up. So in pouring silvery iron it is especially important to pour it hot.

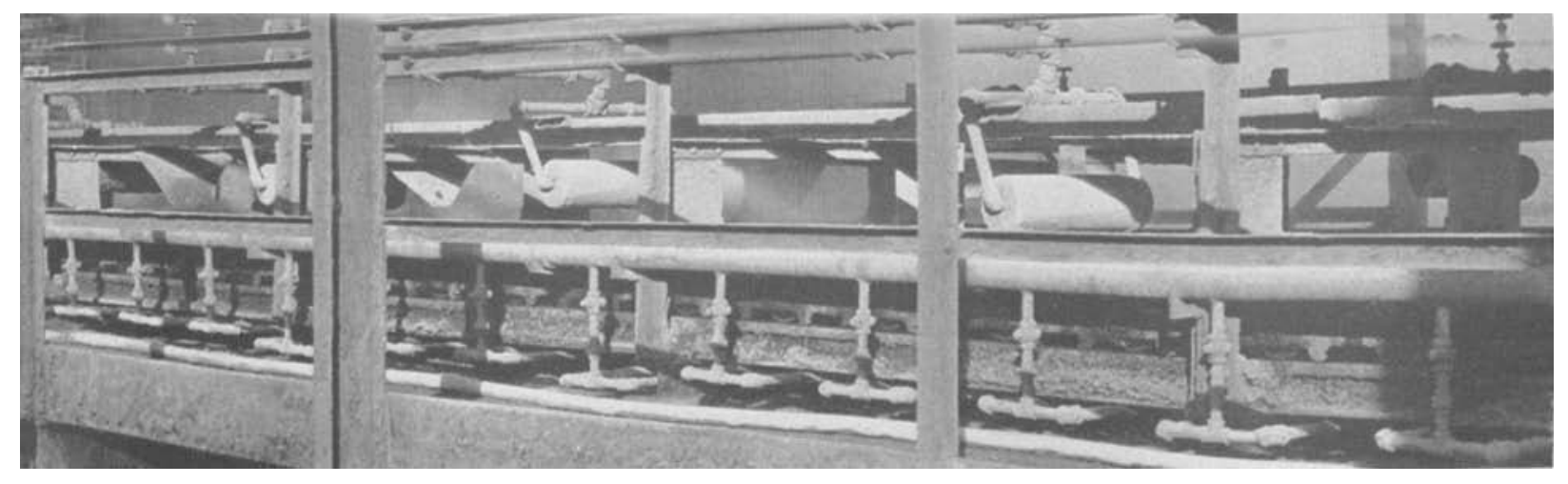

Water box cooling sprays and piping for undercooling. 